\title{
Angewandte
}

Supporting Information

(C) Wiley-VCH 2014

69451 Weinheim, Germany

\section{On-Chip Spyhole Mass Spectrometry for Droplet-Based} Microfluidics**

Natalia Gasilova, Qiuliyang Yu, Liang Qiao, and Hubert H. Girault*

anie_201310795_sm_miscellaneous_information.pdf anie_201310795_sm_spyhole_estasi.m4v 


\section{Supporting Information}

Table of content:

Chemicals and materials

SI-1: Microfluidic set-up optimization.

SI-2: Optimization of droplets formation.

SI-3: Sample carry-over experiment for spyhole ESTASI.

SI-4: Tryptic digestion in droplets.

SI-5: $\beta$-lactoglobulin and $\alpha$-tocopheryl acetate interaction.

SI-6: Tandem MS of $\alpha$-tocopheryl acetate and its oxidation product

SI-7: Tagging free cysteine residues in the reduced $\beta$-lactoglobulin with benzoquinone.

References 


\section{Chemicals and materials}

Angiotensin I (trifluoroacetate salt, 98\%), was obtained from Bachem (Dübendorf, Switzerland). Cytochrome C from horse heart ( $\geq 90 \%$ ), 1,2-dichloroethane (DCE, $\geq 99.5 \%$ ) and 1,4-benzoquinone $(\geq 99.5 \%)$ were purchased from Fluka (Buchs, Switzerland). Trypsin (from bovine pancreas) was obtained from Applichem (Darmstadt, Germany). ACTH (1-24, human) was purchased form AnaSpec (Fremont, CA, USA). Bovine $\beta$-lactoglobulin (A+B, 90\%), DL- $\alpha-$ tocopheryl acetate $(\geq 96 \%)$, tyrosine-tyrosine hydrochloride, lysine-valine hydrochloride, acetylL-lysine, DL-dithiothretiol ( $\geq 99.0 \%$ ) were purchased from Sigma-Aldrich (Buchs, Switzerland). Acetic acid (99.5\%) and ammonium bicarbonate (99.5\%) were purchased from Fluka (Buchs, Switzerland). Methanol (99.9\%), tetradecane ( $\geq 99.0 \%)$, and perfluorodecalin $(95 \%)$ were obtained from Sigma-Aldrich (Buchs, Switzerland). For sample solutions and all experiments, deionized water produced by an alpha Q-Millipore System (Zug, Switzerland) was used.

For microchip fabrication polyimide Kapton was purchased from DuPont (Geneva, Switzerland), while polyethylene/polyethylene terephalate (PE/PET) composite sheet for lamination was obtained from Morane Senator (Oxon, UK).

During the experiments droplets were generated in the fused silica capillaries (75 $\mu \mathrm{m}$ i.d, BGB analytik AG, Böckten, Switzerland) using T-junction (IDEX Health and Science LLC, Oak Harbor, WA, USA) and were transferred to the spyhole microchip via a homemade plastic holder with tight fittings (IDEX Health and Science LLC, Oak Harbor, WA, USA). The water and DCE phases were injected into the capillaries using glass syringes (Hamilton, Bonaduz, Switzerland) by the syringe pumps (Cole Palmer Instrument Company, Vernon Hills, USA) at flow rates of 75 $\mu \mathrm{L} / \mathrm{h}$ and $45 \mu \mathrm{L} / \mathrm{h}$, respectively.

Mass spectrometer (Thermo LTQ Velos, Thermo Scientific, San Jose, USA) was always operated in a positive ion mode. Its ion transfer capillary of was bended for the horizontal positioning of the spyhole microchip. ESTASI MS analysis of all the samples was performed with $8 \mathrm{kV}$ amplitude and $10 \mathrm{~Hz}$ frequency of high voltage pulses. Voltage pulses (0 to $8 \mathrm{kV}$ ) were generated by a function generator and a high voltage amplifier (10HVA24-P1, HVP High Voltage Products GmbH, Martinsried/Planegg, Germany). 


\section{SI-1. Microfluidic set-up optimization}

Microchip with a spyhole was fabricated by laser ablation of a polyimide (PI) substrate as described elsewhere. ${ }^{[1,2]}$ The thickness of used PI substrate was $125 \mu \mathrm{m}$. After drilling a main channel, the spyhole was drilled from the same side using a round-shaped mask. Therefore, after the PE/PET lamination of the PI substrate on the side with the main channel, the spyhole remained open. The microchip design is presented on Figure SI-1.1.

a)

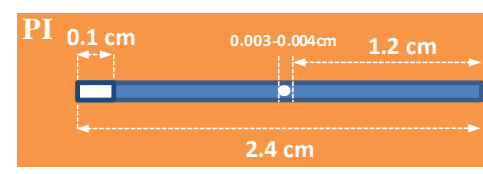

b)

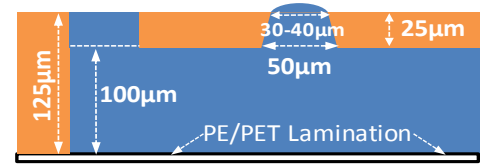

c)

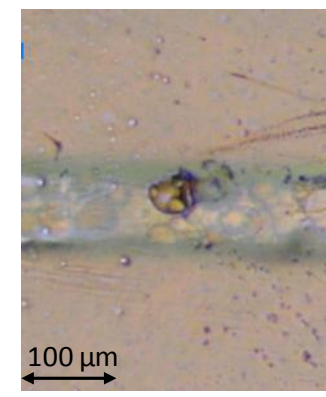

d)

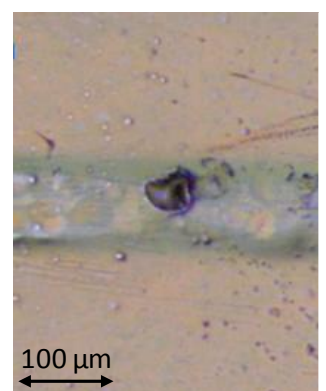

Figure SI-1.1. Microchip with a spyhole. Schemes of a) top and b) longitudinal views of the PI microchip with the spyhole. Photos of the spyhole in the microchip when a) the water droplet passes it by (light spot in the spyhole), and b) oil plug passes it by (dark spot in the spyhole). The photos were made by a laser scanning microscope VK-8710 (Keyence Corporation, Osaka, Japan).

In the laser ablation process, the channel width was fixed by the size of the ablation mask used for its drilling. The depth of the microchannel was defined by the speed of the substrate translation and was measured by a laser scanning microscope VK-8710 (Keyence Corporation, Osaka, Japan). As can be concluded from Figure SI-1.1.b, the depth of the spy hole depended on the microchannel depth and microchip thickness. Theoretically, the spyhole diameter should be determined by the size of the mask used for its drilling and be the same for inner and outer parts of the microchip. However, due to the small size of the mask and laser energy dispersion during the ablation process, only the inner diameter of the hole corresponded to the mask dimensions. The outer diameter was smaller, than the mask, providing a cone-like shape for the spyhole in longitudinal view (Figure SI-1.1.b).

In order to obtain stable electrostatic spray from the spyhole without any solution leakage, such parameters as a spyhole diameter, microchannel depth and width were optimized. Tested values of these parameters are presented below in Table SI-1. The values for spyhole diameter correspond to the inner diameter defined by the size of the ablation mask. The evaluation of the microchip was made based on the ESTASI performance from the continuous sample flow, typically of $3 \mu \mathrm{M}$ angiotensin I in ESI solution at $75 \mu \mathrm{l} / \mathrm{h}$. The number of electrostatic sprays per minute coming out from the spyhole and the minimal value of signal-to-noise $(\mathrm{S} / \mathrm{N})$ ratio for 
single cation current (SCC) of angiotensin I cations were used for ESTASI performance description.

Table SI-1. Tested microchip parameters.

\begin{tabular}{|c|c|c|c|c|c|c|c|c|c|}
\hline $\begin{array}{c}\text { Channel } \\
\text { width, } \mu m\end{array}$ & $\begin{array}{c}\text { Channel } \\
\text { depth, } \\
\mu \mathrm{m}\end{array}$ & $\begin{array}{c}\text { Hole } \\
\text { Diameter, } \\
\mu m\end{array}$ & $\begin{array}{l}\text { Sprays } \\
\text { per min }\end{array}$ & $\begin{array}{c}S C C \\
\text { min } S / N \\
\text { ratio } \\
\end{array}$ & $\begin{array}{l}\text { Channel } \\
\text { width, } \mu m\end{array}$ & $\begin{array}{l}\text { Channel } \\
\text { depth, } \mu m\end{array}$ & $\begin{array}{c}\text { Hole } \\
\text { Diameter, } \\
\mu \mathrm{m}\end{array}$ & $\begin{array}{l}\text { Sprays } \\
\text { per min }\end{array}$ & $\begin{array}{c}S C C \\
\text { min } S / N \\
\text { ratio } \\
\end{array}$ \\
\hline \multirow{8}{*}{100} & \multirow{3}{*}{25} & - & \multirow{3}{*}{0} & \multirow{3}{*}{-- } & \multirow{8}{*}{200} & \multirow{4}{*}{66} & 21.5 & \multirow{4}{*}{$\leq 6$} & \multirow{4}{*}{$\leq 2$} \\
\hline & & 21.5 & & & & & 30 & & \\
\hline & & 50 & & & & & 40 & & \\
\hline & \multirow{3}{*}{50} & 5.5 & \multirow{2}{*}{0} & \multirow{2}{*}{-- } & & & 50 & & \\
\hline & & 21.5 & & & & \multirow{4}{*}{100} & 21.5 & \multirow{4}{*}{$\leq 10$} & \multirow{4}{*}{$\leq 2$} \\
\hline & & 50 & 7 & 2 & & & 30 & & \\
\hline & \multirow{2}{*}{100} & 5.5 & 0 & - & & & 40 & & \\
\hline & & 21.5 & 6 & 3 & & & 50 & & \\
\hline
\end{tabular}

For a microchannel width of $200 \mu \mathrm{m}$, none of the parameter combinations shown in Table SI-1, provided efficient electrostatic spray without solution leakage from the spyhole. Even the presence of swab stick at the microchip outlet could not prevent the solution from coming out of the spyhole. An example of obtained TCC and SCC chromatograms, as well as an ESTASI MS spectrum is shown in Figure SI-1.2.

a)

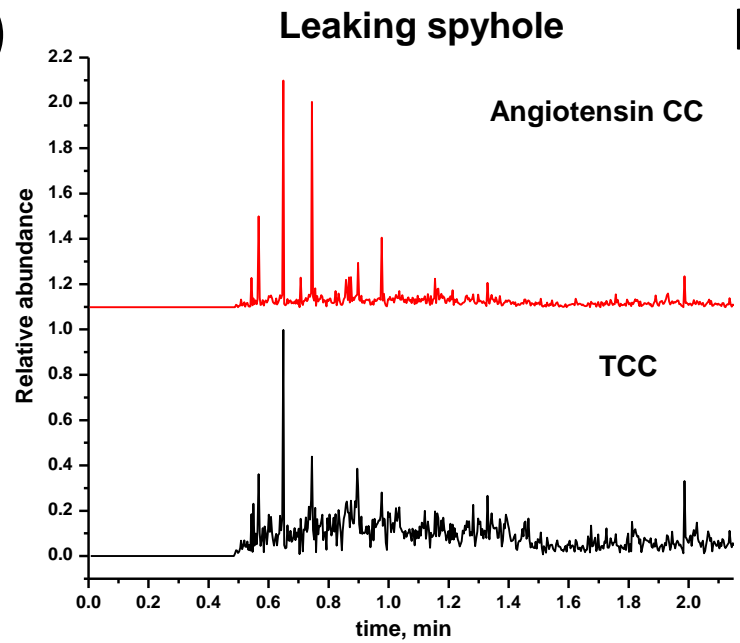

b)

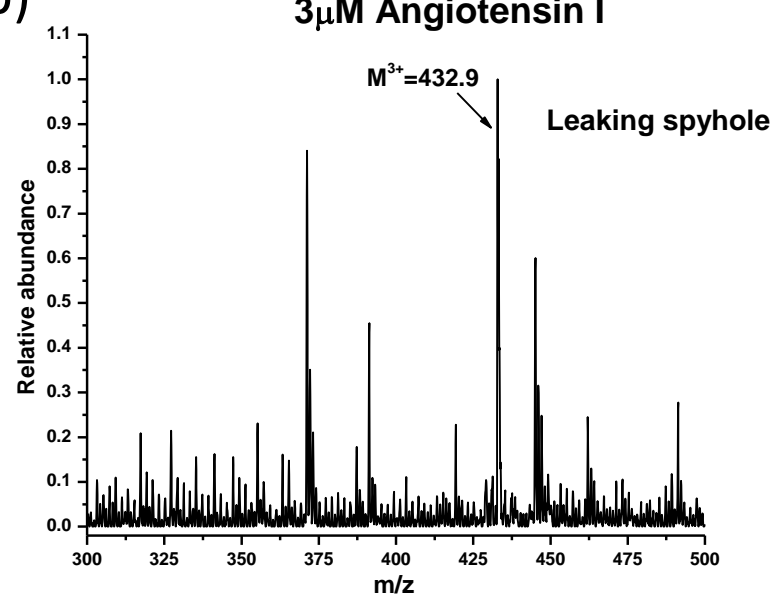

Figure SI-1.2. Spyhole microchips evaluation by ESTASI performance, example of a leaking spyhole. a) TCC and SCC chromatograms, b) ESTASI MS spectrum. Sample: $3 \mu \mathrm{M}$ angiotensin I in ESI solution at $75 \mu / \mathrm{h}$. High voltage frequency: $10 \mathrm{~Hz}$.

Such microchips displayed poor ESTASI efficiency with $\leq 6$ sprays per minute and low minimal S/N ratio for SCC because of the sample solution leakage from the spyhole. Such leakage leaded to the formation of a large solution drop difficult to be sprayed and yielding a noisy MS spectrum (Figure SI-1.2.b). Therefore, a $100 \mu \mathrm{m}$ channel width was chosen for further experiments. Its combination, along with the microchannel depth of $25 \mu \mathrm{m}$, insured the absence of solution leakage, but no spray was observed because of the large value of spyhole depth, 100 $\mu \mathrm{m}$. Variation of the hole diameter did not provide any improvements in this case. 

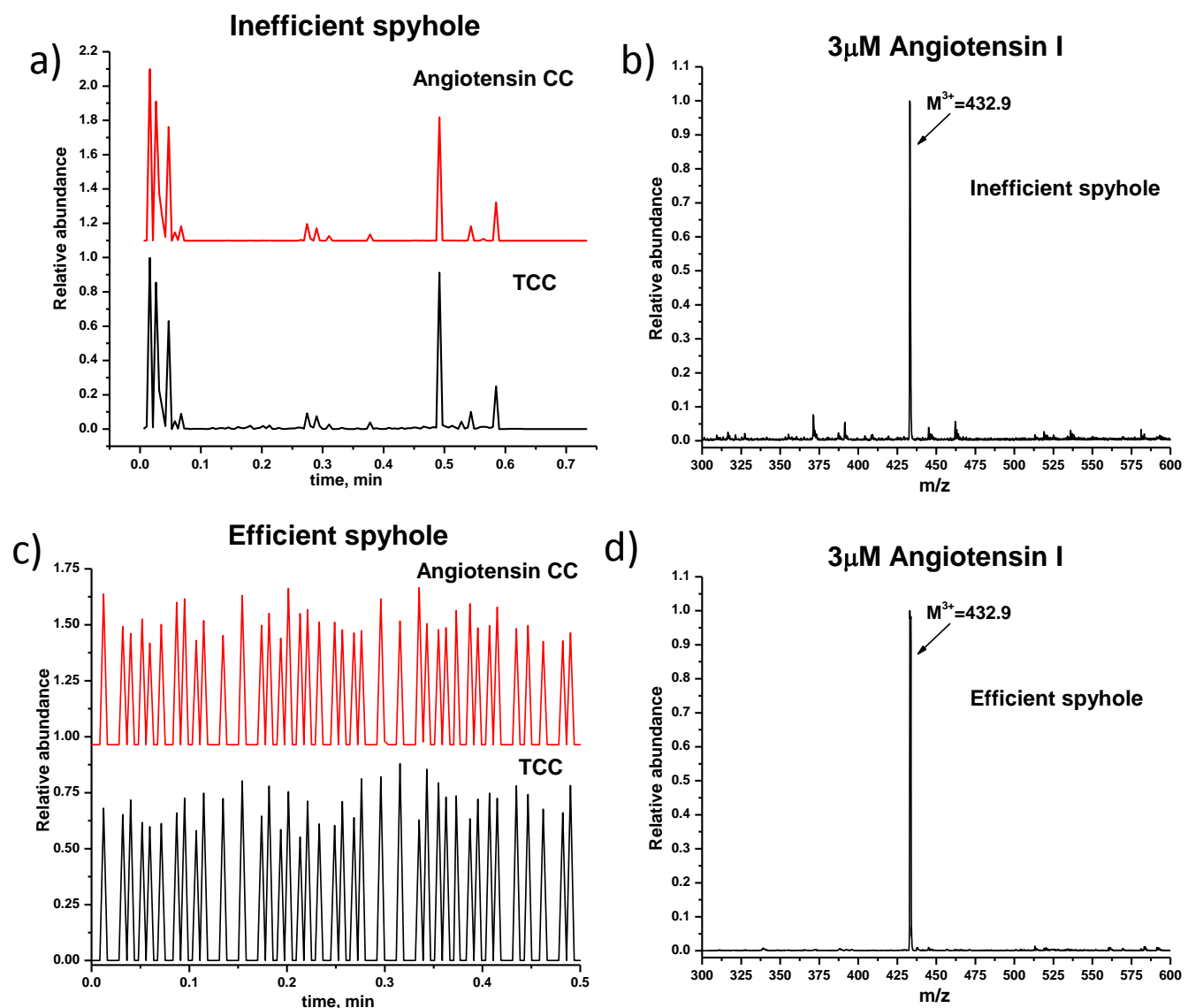

Figure SI-1.3. Spyhole microchips evaluation by ESTASI performance. Inefficient spyhole, 100 $\mu \mathrm{m}$ main channel width, $50 \mu \mathrm{m}$ main channel depth and $50 \mu \mathrm{m}$ spyhole diameter: a) TCC and SCC chromatograms, b) ESTASI MS spectrum. Efficient spyhole, $100 \mu \mathrm{m}$ main channel width, $100 \mu \mathrm{m}$ main channel depth and $50 \mu \mathrm{m}$ spyhole diameter: c) TCC and SCC chromatograms, signal frequency of $1.5 \mathrm{~Hz}$, d) ESTASI MS spectrum. Sample: $3 \mu \mathrm{M}$ angiotensin I in ESI solution at $75 \mu / \mathrm{h}$. High voltage frequency: $10 \mathrm{~Hz}$.

Increasing of the microchannel depth to $50 \mu \mathrm{m}$ led to the decrease of spyhole depth to 75 $\mu \mathrm{m}$ and allowed some electrostatic spray when the spyhole diameter was $50 \mu \mathrm{m}$, but in an inefficient manner with only 7 sprays per min and with minimal S/N ratio for SCC of 2 (Figure SI-1.3.a and b). The most efficient and stable electrostatic spray with signal frequency of $1.5 \mathrm{~Hz}$ was observed only when the microchannel depth was increased to $100 \mu \mathrm{m}$, the spyhole depth and inner diameter were $25 \mu \mathrm{m}$ and $50 \mu \mathrm{m}$, respectively (Figure SI-1.3.c and d). The outer diameter of the spyhole was measured to be between 30 and $40 \mu \mathrm{m}$, depending on the microchips produced (Figure SI-1.1.d). When swab stick was used for solution collection at the microchip outlet, no leakage from the spyhole was observed for this microchip configuration if total flow rate of the solution was $\leq 150 \mu / \mathrm{h}$.

These microchip parameters used for further experiments provided effective sample ionization with high detection sensitivity, minimal S/N ratio for SCC of 3000 and RSD for TCC and SCC intensities of $15 \%$ and $16 \%(n=30)$, respectively. For continuous sample flow at 75 
$\mu \mathrm{l} / \mathrm{h}$ inside the microchip, the limit of detection (value of $3 \mathrm{~S} / \mathrm{N}$ ratio) by ESTASI MS was defined as $5 \mathrm{nM}$ for peptide angiotensin I and $30 \mathrm{nM}$ for protein cytochrome $\mathrm{C}$ (Figure SI-1.4).
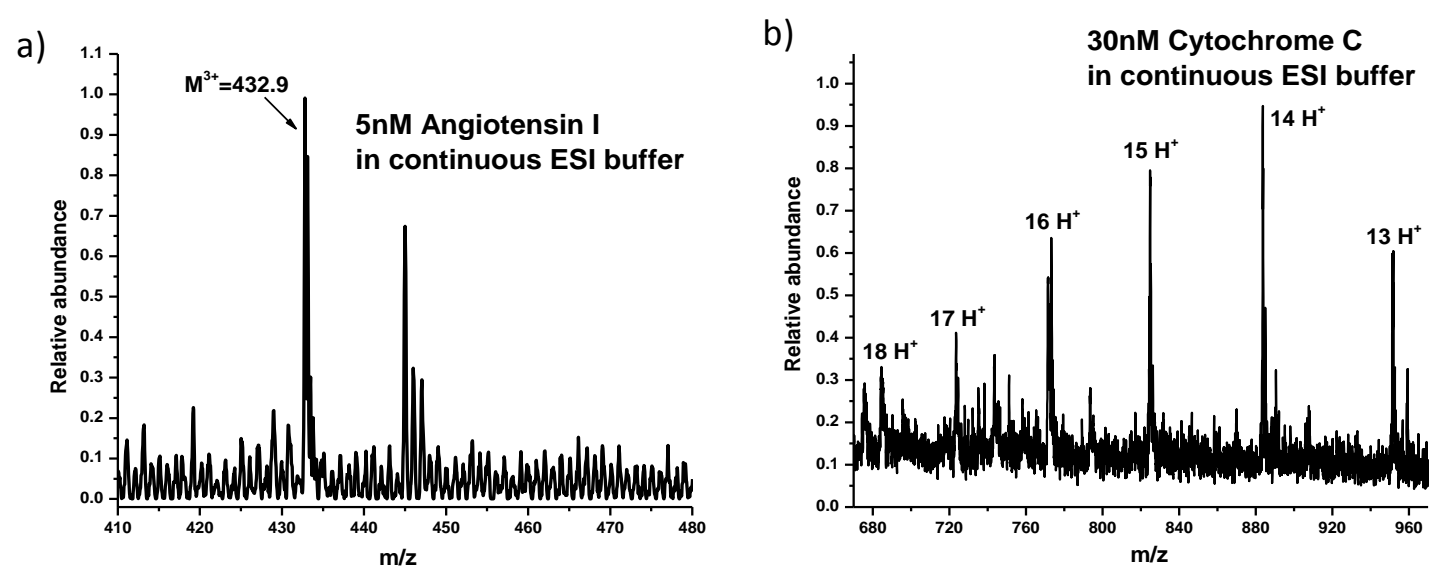

Figure SI-1.4. Limit of detection for ESTASI MS analysis of continuous sample flow at $75 \mu 1 / \mathrm{h}$ inside the microchip with a spyhole. a) $5 \mathrm{nM}$ angiotensin I, b) $30 \mathrm{nM}$ of cytochrome C. Sample solutions were containing 50\% methanol, $49 \%$ deionized water, and $1 \%$ acetic acid.

To perform the ESTASI in the system under consideration, voltage square wave pulses with the amplitude of $8 \mathrm{kV}$ were normally applied to the electrode placed under the microchip using a function generator with a voltage amplifier (10HVA24-P1, HVP High Voltage Products $\mathrm{GmbH}$, Martinsried/Planegg, Germany). The typical square wave frequency was $10 \mathrm{~Hz}$, meaning that during the first $50 \mathrm{~ms}$ (charging of the capacitors) high voltage pulse provoked the electrostatic spray of cations and during the last $50 \mathrm{~ms}$ electrostatic spray of anions was elicited (discharging of the capacitors). ${ }^{[1]}$ It provided for the continuous sample flow the TCC signal with average frequency of $\sim 1.5 \mathrm{~Hz}$, as displayed in Figure SI-1.3.c. This TCC average signal frequency was determined by the combination of the square voltage wave frequency with the scanning frequency of the ion trap mass spectrometer (Thermo Scientific, San Jose, USA) employed in a positive mode. Taking into account that the maximum ion injection time for the ion trap was set to $100 \mathrm{~ms}$ following the high voltage frequency of $10 \mathrm{~Hz}$ and that an enhanced scanning mode $(\mathrm{m} / \mathrm{z}, 10000$ per second) was used, it took $\sim 333 \mathrm{~ms}$ for the instrument to generate each spectrum for the spray of cations. 


\section{SI-2: Optimization of droplets formation}

\section{Choice of oil phase}

The choice of oil phase is crucial for coupling the water-in-oil droplet system to the MS detection as the oil presence compromises ionization efficiency and ESI plume stability. ${ }^{[3]}$ Various components were tried as the oil phase in the present droplet-based system with droplet generation frequencies of $\sim 0.5 \mathrm{~Hz}$ that are listed in Table SI-2. It is worth mentioning that prior to any oil injection into the main channel of the microchip, it was treated with Aquapel, commercial water repellant, for surface hydrophobization and better oil adhesion.

Table SI-2. Oil phase used for droplets formation.

\begin{tabular}{|c|c|c|c|c|}
\hline \multicolumn{2}{|c|}{ Compound } & $\begin{array}{c}\text { Tetradecane } \\
\text { (TD) }\end{array}$ & $\begin{array}{c}\text { Perfluorodecalin } \\
\text { (PFD) }\end{array}$ & $\begin{array}{c}\text { 1,2-dichloroethane } \\
\text { (DCE) }\end{array}$ \\
\hline $\begin{array}{c}\text { Dynamic viscosity at } 25^{\circ} \mathrm{C}, \mathrm{mPa} \cdot \mathrm{s} \\
\text { Methanol for comparison: } 0.56\end{array}$ & 2.1 & 5.1 & 0.78 \\
\hline $\begin{array}{c}\text { Droplets frequency: } \\
0.5 \mathrm{~Hz}\end{array}$ & Sprays per min & -- & 6 & 20 \\
\cline { 2 - 5 } & SCC min S/N ratio & -- & $\leq 1.5$ & 50 \\
\hline
\end{tabular}

Long carbon chain compounds, like TD, introduced as an oil phase at $30 \mu \mathrm{l} / \mathrm{h}$ quenched ESTASI. Therefore, no ESTASI MS signal was observed from droplets containing $3 \mu \mathrm{M}$ angiotensin I in ESI solution introduced as aqueous phase at $15 \mu \mathrm{l} / \mathrm{h}$. Viscosity of this compound is much higher than for traditional ESI solvents such as methanol (Table SI-2) and significantly compromises electrostatic spray. PFD is widely used as oil phase for droplet-based microfluidics with ESI MS detection due to its low interference with the ESI plume ${ }^{[3-6]}$ and was tried as an oil phase for spyhole ESTASI MS system as well. Droplets were generated with PFD introduced as an oil phase at $30 \mu \mathrm{l} / \mathrm{h}$, while the water phase was introduced at $15 \mu \mathrm{l} / \mathrm{h}$. Obtained results are presented in Figure SI-2.1.
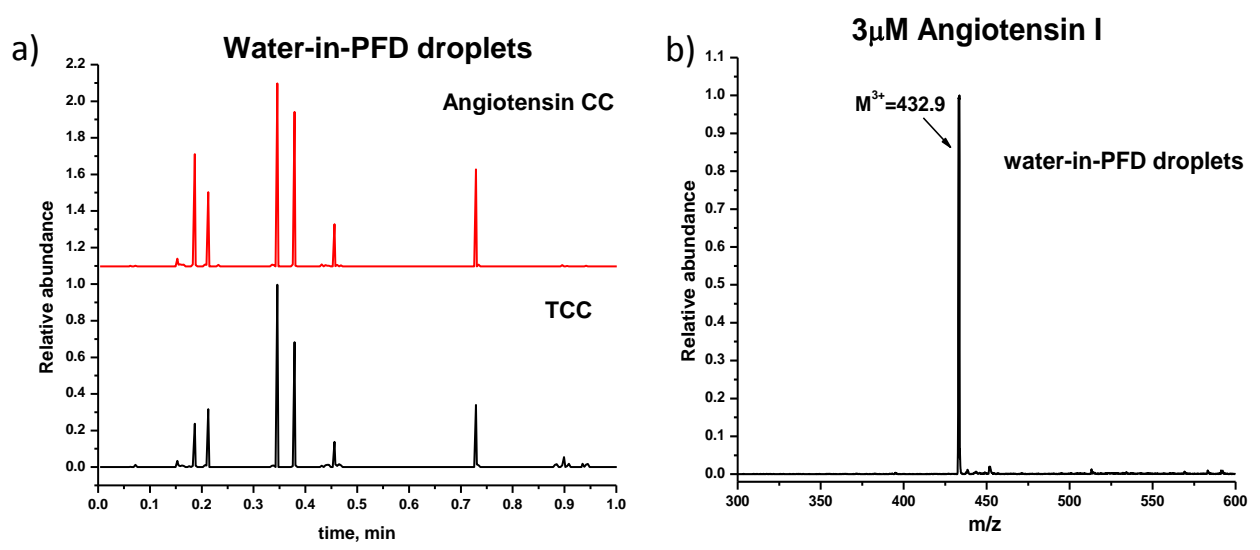

Figure SI-2.1. Spyhole ESTASI of water-in-PFD droplets. a) TCC and SCC chromatograms, b) ESTASI MS spectrum. Sample: $3 \mu \mathrm{M}$ angiotensin I in ESI solution. Oil and water phase rates: $30 \mu / \mathrm{h}$ and $15 \mu / \mathrm{h}$, respectively. High voltage frequency: $10 \mathrm{~Hz}$. Droplets frequency $\sim 0.5 \mathrm{~Hz}$. 
PFD as the oil phase did not quench the electrostatic spray from the spyhole and provided MS spectra with sufficient signal intensity, but the spray was unstable and displayed only 6 sprays per minute. As the outer diameter of the spyhole was only $30 \mu \mathrm{m}$, PFD still influenced significantly the plume formation.

DCE is a very well known solvent immisible in water, widely used for physicochemical studies of various processes at liquid-liquide interfaces, ${ }^{[7-9]}$ including the creaction of biomembrane mimetic model to study the trans-cell membrane biological reactions. ${ }^{[10,11]}$ DCE possesses the lowest viscosity among tested compounds with a value of $0.78 \mathrm{mPa} \cdot \mathrm{s}$, close to methanol with $0.56 \mathrm{mPa} \cdot \mathrm{s}$ and is immiscible with water; therefore, it was also tried as the oil phase and showed the best spyhole ESTASI performance for droplets generated with $0.5 \mathrm{~Hz}$ frequency (Figure SI-2.2). DCE was introduced into the T-junction at $80 \mu \mathrm{l} / \mathrm{h}$ along with the water phase at $50 \mu \mathrm{l} / \mathrm{h}$.
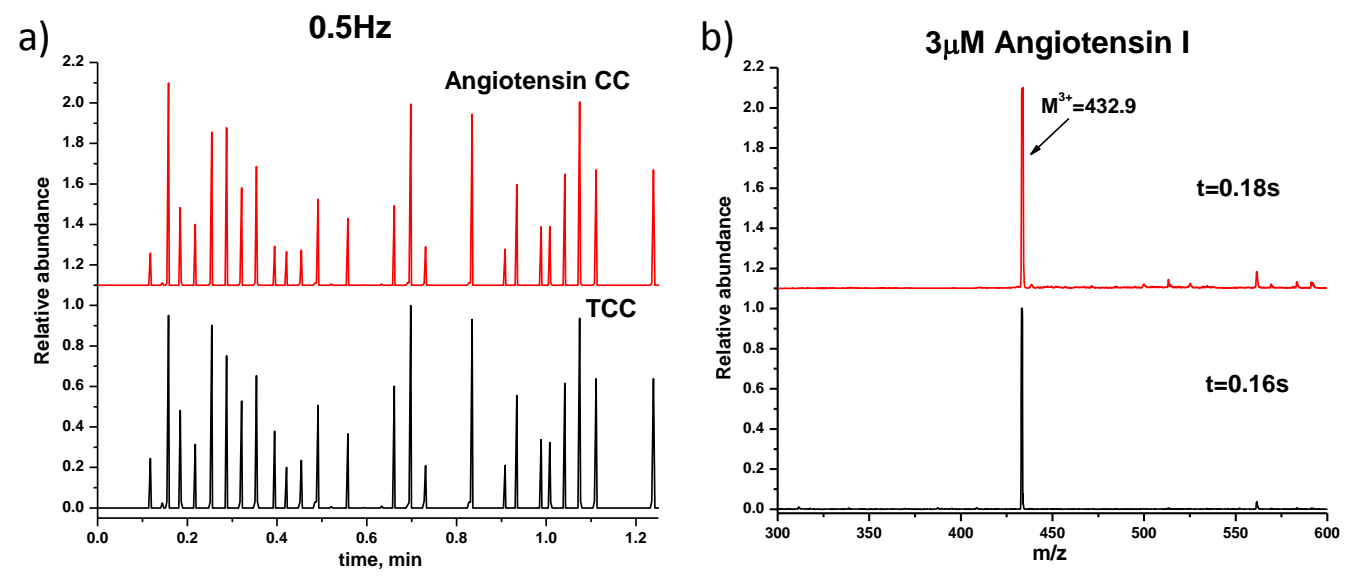

Figure SI-2.2. Spyhole ESTASI of water-in-DCE droplets. a) TCC and SCC chromatograms, b) ESTASI MS spectrum. Sample: $3 \mu \mathrm{M}$ angiotensin I in ESI solution. Oil and water phase rates: $80 \mu \mathrm{l} / \mathrm{h}$ and $50 \mu \mathrm{l} / \mathrm{h}$, respectively. High voltage frequency: $10 \mathrm{~Hz}$. Droplets frequency $\sim 0.5 \mathrm{~Hz}$.

With DCE as oil phase the number of sprays per minute increased to 20 and minimal S/N ratio for SCC was giving a value of 50, so this solvent was chosen for further experiments with droplets. The issues with the reproducibility of TCC, SCC, MS signal intensities and spray stability were further addressed and resolved as described below in the section Droplet frequency optimization .

Prior to the optimization of droplets generation, DCE was tested on the possible sample diffusion into such oil phase, as it is more polar than conventional oil phases, like PFD or TD. For this purpose, a shake flask experiment was performed separately for the following compounds used further in the present work: $3 \mu \mathrm{M}$ angiotensin I, $10 \mu \mathrm{M}$ cytochrome $\mathrm{C}, 10 \mu \mathrm{M}$ human ACTH (1-24), $5.4 \mu \mathrm{M} \beta$-lactoglobulin (A and B isoforms) and $5 \mu \mathrm{M}$ peptide TVSFNF. $200 \mu \mathrm{l}$ of water solution of each compound was brought into contact with $200 \mu \mathrm{l}$ of DCE in a 0.5 
$\mathrm{ml}$ eppendorf tube, which was then vortexed for $3 \mathrm{~min}$. Subsequently, the emulsion of water/DCE was centrifuged at $10000 \mathrm{~g}$ for $30 \mathrm{sec}$ for better separation of the phases; each phase was then spotted separately on a MALDI plate and dried at the room temperature. After matrix solution addition and spots drying, MALDI MS analysis of water and DCE phases was performed to check the presence of the compound of interest. For peptide MALDI MS analysis $10 \mathrm{mg} / \mathrm{ml}$ solution of 2,5-dihydroxybenzoic acid in $50 \%$ acetonitril, $49.9 \%$ water, $0.1 \%$ trifluoroacetic acid was used, while $2 \mathrm{mg} / \mathrm{ml}$ sinapinic acid solution in $70 \%$ acetonitril, $29.9 \%$ water, $0.1 \%$ trifluoroacetic acid was used for the proteins.
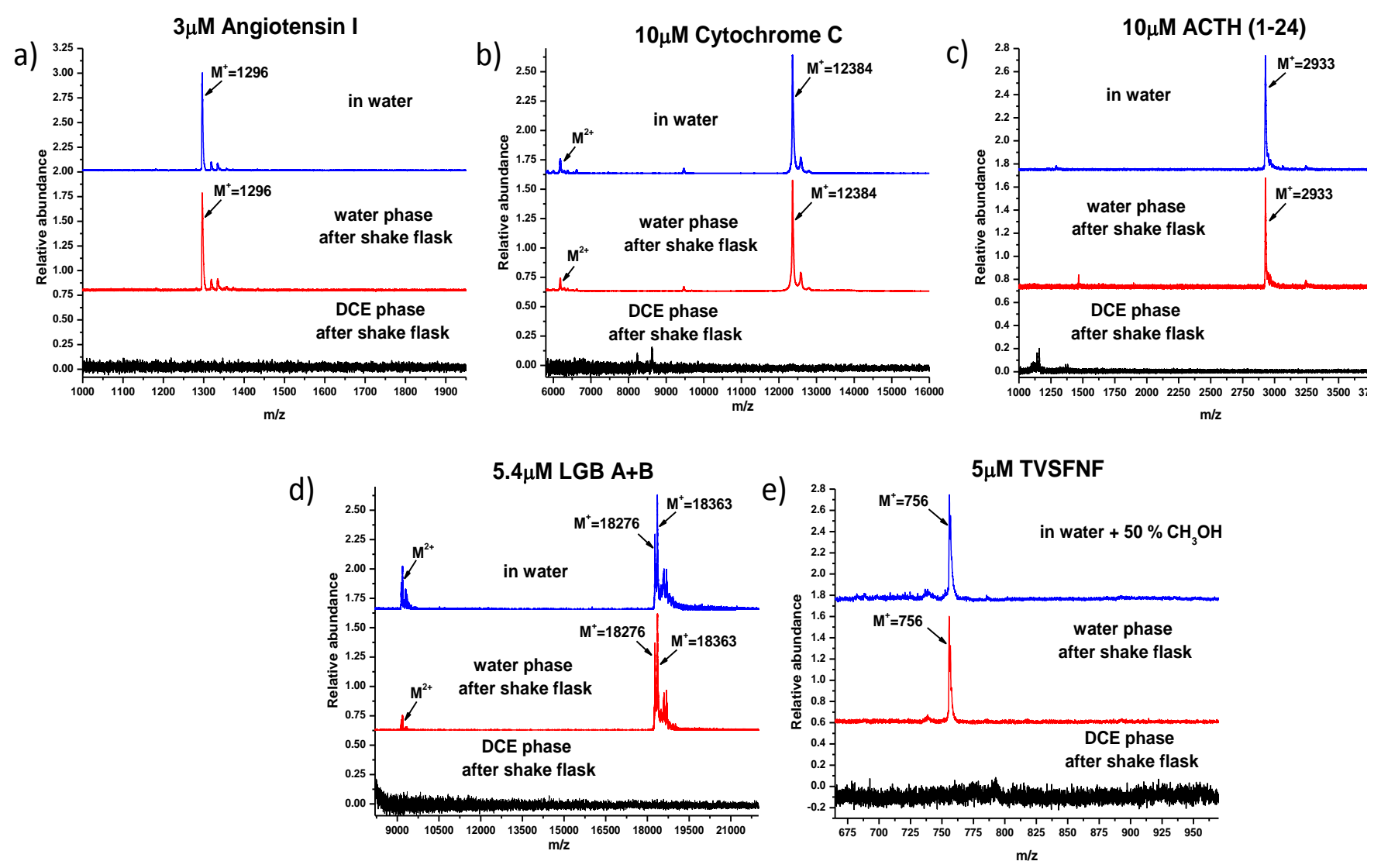

Figure SI-2.3. MALDI MS spectra of DCE polarity test on sample diffusion. Sample: a) $3 \mu \mathrm{M}$ angiotensin I, b) $10 \mu \mathrm{M}$ cytochrome C, c) $10 \mu \mathrm{M}$ human ACTH (1-24), d) $5.4 \mu \mathrm{M} \beta$ lactoglobulin $(\mathrm{A}+\mathrm{B})$ and e) $5 \mu \mathrm{M}$ peptide TVSFNF. Blue spectra represent the water phase content before shake-flask experiment, while red and black spectra correspond to after-shakeflask experiment content of water and oil phases, respectively.

MALDI MS detection was chosen for this experiment in order to analyze the DCE phase, as in the ESI MS this solvent is very difficult to be ionized and does not give any signal. As can be concluded from the obtained results of shake-flask experiment, none of the tested compounds diffused to the DCE phase: peptides and proteins were observed only in the water phase. Even hydrophobic peptide, such as TVSFNF, for which the stock solution contained $50 \%$ methanol to increase its solubility in water, did not diffuse into the DCE phase and was observed only on the 
MALDI MS spectrum of the aqueous phase (Figure SI-2.3.e). DCE application as the oil phase does not lead to sample diffusion into this phase; therefore, this solvent was used for further experiments.

\section{Droplet frequency optimization}

In the case of water-in-oil droplets coupling with ESTASI MS via the described microchip, the synchronization between droplet generation frequency, voltage pulse frequency and MS scans would provide the advantage of avoiding voltage application to the oil segments and energy saving. To achieve synchronization, it was required that the high voltage activation occurred only when the water droplet was under the spyhole. In the described experiments, we have tried manually to realize the synchronization by droplets visual control using a portable digital microscope (Dino-Light, Amno, Taiwan); however, it remained challenging. Therefore, the frequencies $\leq 0.5 \mathrm{~Hz}$, significantly lower than $1.5 \mathrm{~Hz}$ (spyhole ESTASI signal frequency from the continuous sample flow, SI-1) were chosen for droplet generation to insure by default the ionization and detection of all formed droplets, to have preferably one spray per droplet and providing sufficient time between two droplets for the MS instrument to respond on the sample electrostatic spray and finish the measurement.

As presented in Figure SI-2.2, the TCC and SCC (RSD=60\%, $n=20)$ signals from waterin-DCE droplets formed with $0.5 \mathrm{~Hz}$ frequency were unstable, potentially due to the absence of the good matching with the timing of high voltage pulses. Lower frequencies of $0.3 \mathrm{~Hz}$ and 0.1 $\mathrm{Hz}$ were also tried for droplet generation. For $0.3 \mathrm{~Hz}$ DCE was injected at $60 \mu \mathrm{l} / \mathrm{h}$ and the water phase was introduced at $75 \mu \mathrm{l} / \mathrm{h}$. For $0.1 \mathrm{~Hz}$ DCE was injected at $45 \mu \mathrm{l} / \mathrm{h}$ and aqueous was introduced at $75 \mu \mathrm{l} / \mathrm{h}$. Obtained results are shown in Figure SI-2.4.
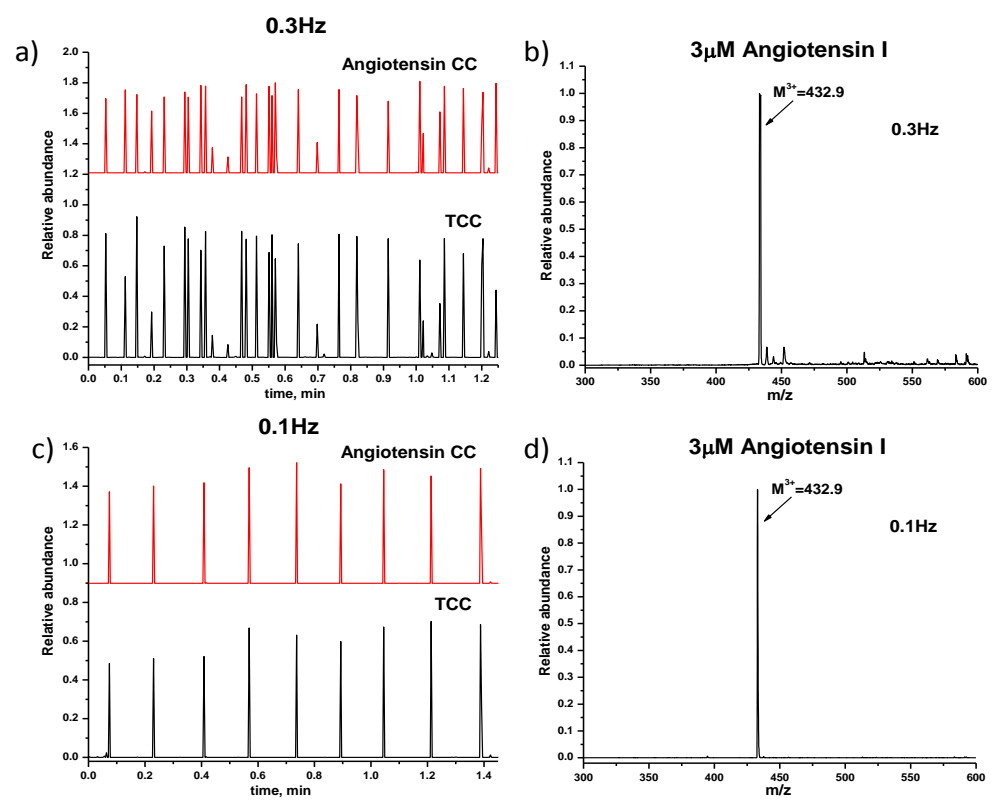

Figure SI-2.4. Spyhole ESTASI of water-in-DCE droplets. Droplets frequency: a) $0.3 \mathrm{~Hz}$ and b) $0.1 \mathrm{~Hz}$. Sample: $3 \mu \mathrm{M}$ angiotensin I in ESI solution. High voltage frequency: $10 \mathrm{~Hz}$. 
For droplet generation frequency of $0.3 \mathrm{~Hz}$ better reproducibility for TCC and SCC intensities ( $\mathrm{RSD}=30 \%, \mathrm{n}=20$ ) was obtained, however, signal frequency was still unstable. The droplet generation frequency of $0.1 \mathrm{~Hz}$ provided the most stable TCC (RSD=16\%, $\mathrm{n}=20$ ) and $\mathrm{SCC}(\mathrm{RSD}=15 \%, \mathrm{n}=20)$ signals simultaneously with a stable signal frequency $(0.1 \mathrm{~Hz}, \mathrm{RSD}=5 \%$, $\mathrm{n}=20$ ) in accordance with the droplet generation frequency. As the high voltage frequency was $10 \mathrm{~Hz}$, it took $50 \mathrm{~ms}$ to apply the voltage pulse for positive electrostatic spray. Meanwhile, for a droplet generated at $0.1 \mathrm{~Hz}$ frequency (average volume of $3 \mathrm{nl}, \mathrm{RSD}=7 \%, \mathrm{n}=20$ ) and flow rate of $120 \mu \mathrm{l} / \mathrm{h}$ it took $\sim 100 \mathrm{~ms}$ to pass by the spyhole, indicating that part of the droplet $(\leq 50 \%)$ was submitted to the high voltage pulse. Therefore, there was a good matching between droplets and high voltage frequencies, which insured only one electrostatic spray per droplet and provided reproducible TCC and SCC signals. $0.1 \mathrm{~Hz}$ was chosen as a working frequency for further experiments. 


\section{SI-3: Sample carry-over experiment for spyhole ESTASI}

To check the sample carry-over in the spyhole microchip the concentration gradient was created in the droplets using $5 \mu \mathrm{M}$ acetyllysine (AcLys) solution(A) and $5 \mu \mathrm{M}$ dipeptide TyrTyr solution(B). $5 \mu \mathrm{M}$ of dipeptide Lys Val was presented in both solutions as an internal standard to perform the relative quantification of ESTASI MS results. The gradient of two solutions for water phase was made using liquid chromatography (LC) pump Accela Thermo (Thermo Scientific, San Jose, USA). The gradient program was set to change the ratio between solution A and B from 100:0 to 0:100 within $5 \mathrm{~min}$. The flow rate for LC pump was set to $100 \mu 1 / \mathrm{min}$ and was decreased to $1.25 \mu 1 / \min (75 \mu 1 / \mathrm{h})$ using a Micro-Splitter valve (IDEX Health and Science LLC, Oak Harbor, WA, USA) prior to the introduction to the T-junction as the aqueous phase. DCE was introduced as the oil phase at $45 \mu 1 / \mathrm{h}$. Before starting the gradient program, the system was flushed with solution A for 3 min to insure stable droplets formation. The experiment was performed in triplicates. Obtained SCC chromatograms for AcLys, TyrTyr and internal standard
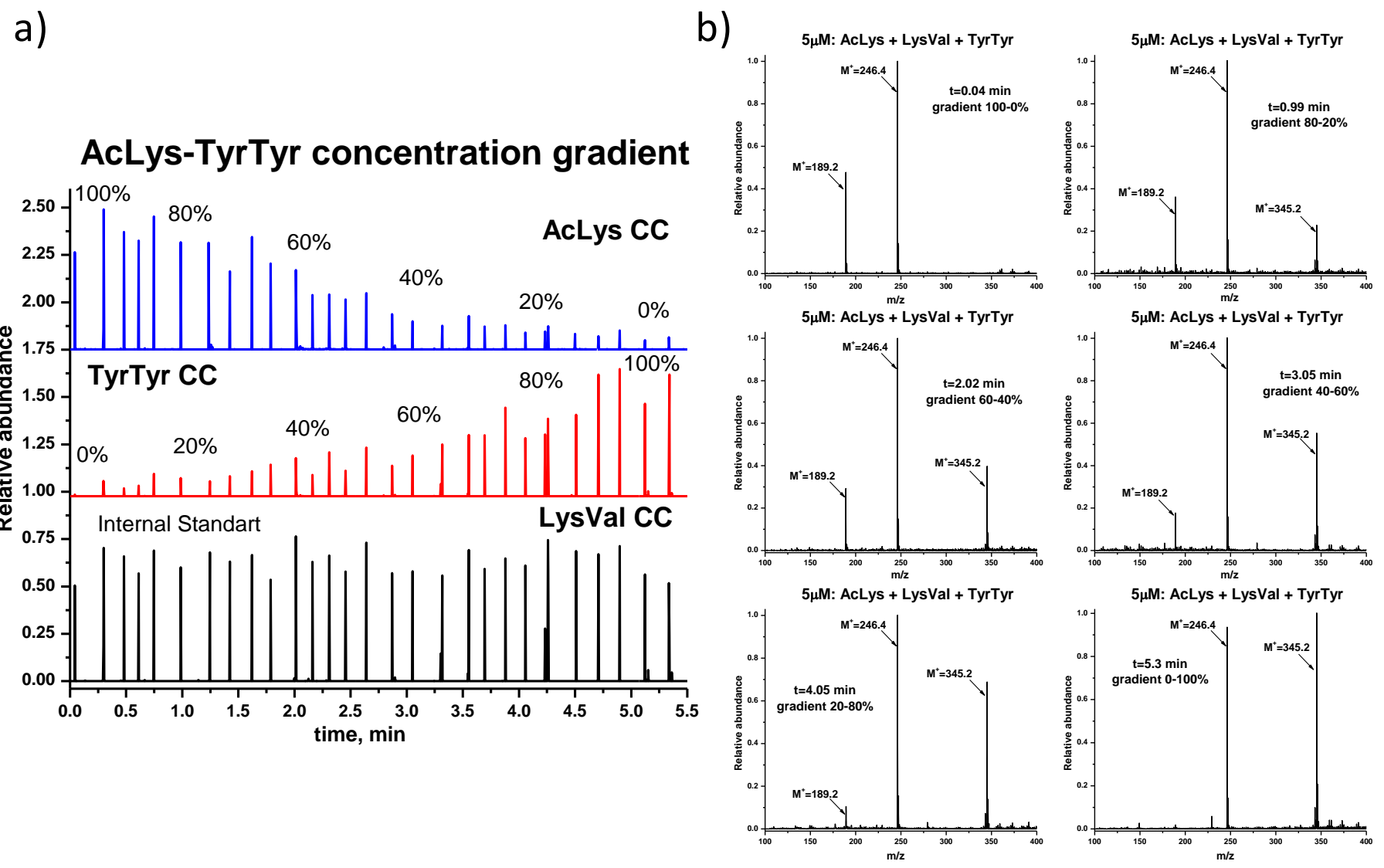

LysVal, as well as corresponding ESTASI MS spectra, are presented in Figure SI-3.

Figure SI-3. Carry-over experiment for spyhole ESTASI with AcLys-TyrTyr concentration gradient. a) SCC chromatograms for AcLys, TyrTyr and LysVal as internal standard. b) ESTASI MS spectra corresponding to the following moments of the gradient program for A and B solutions: $0.04 \mathrm{~min}$ (100:0), $0.99 \mathrm{~min}$ (80:20), $2.02 \mathrm{~min}(60: 40), 3.05 \mathrm{~min}$ (40:60), $4.05 \mathrm{~min}$ (20:80)and $5.3 \mathrm{~min}(0: 100)$. 
It is worth mentioning that in general the ionization efficiency for AcLys is lower than for TyrTyr. As can be observed on ESTASI MS spectra (Figure SI-3.b) for time of 0.04 min corresponding to pure $5 \mu \mathrm{M}$ AcLys solution with internal standard and for time of $5.3 \mathrm{~min}$ corresponding to pure $5 \mu \mathrm{M}$ TyrTyr with internal standard, TyrTyr peak intensity is the same as for LysVal, while for AcLys the peak intensity is two times lower.

As displayed in Figure SI-3, the droplet frequency was $\sim 0.1 \mathrm{~Hz}$ and for the internal standard LysVal, whose concentration remained constant during the experiment, RSD for the SCC intensity was 17\% ( $n=20)$. SCC chromatogram profiles of AcLys and TyrTyr followed the gradient program, as can be also be concluded from the corresponding ESTASI MS spectra (Figure SI-3.b). For the gradient time 5.3 min corresponding to $0 \%$ of solution A and $100 \%$ of solution B small peak of AcLys can still be observed on the ESTASI MS spectrum at the level of the detection limit and shows the carry-over of $6 \%$ for the SCC signal. No leakage from the spyhole was observed during this experiment neither visually, nor on the SCC chromatograms (no high noise level was observed in contrast with the example of leaking spyhole, Figure SI-1.2). Therefore, the carry-over arises mainly from the sample adsorption inside the microfluidic system and LC pump. 


\section{SI-4: Tryptic digestion in droplets}
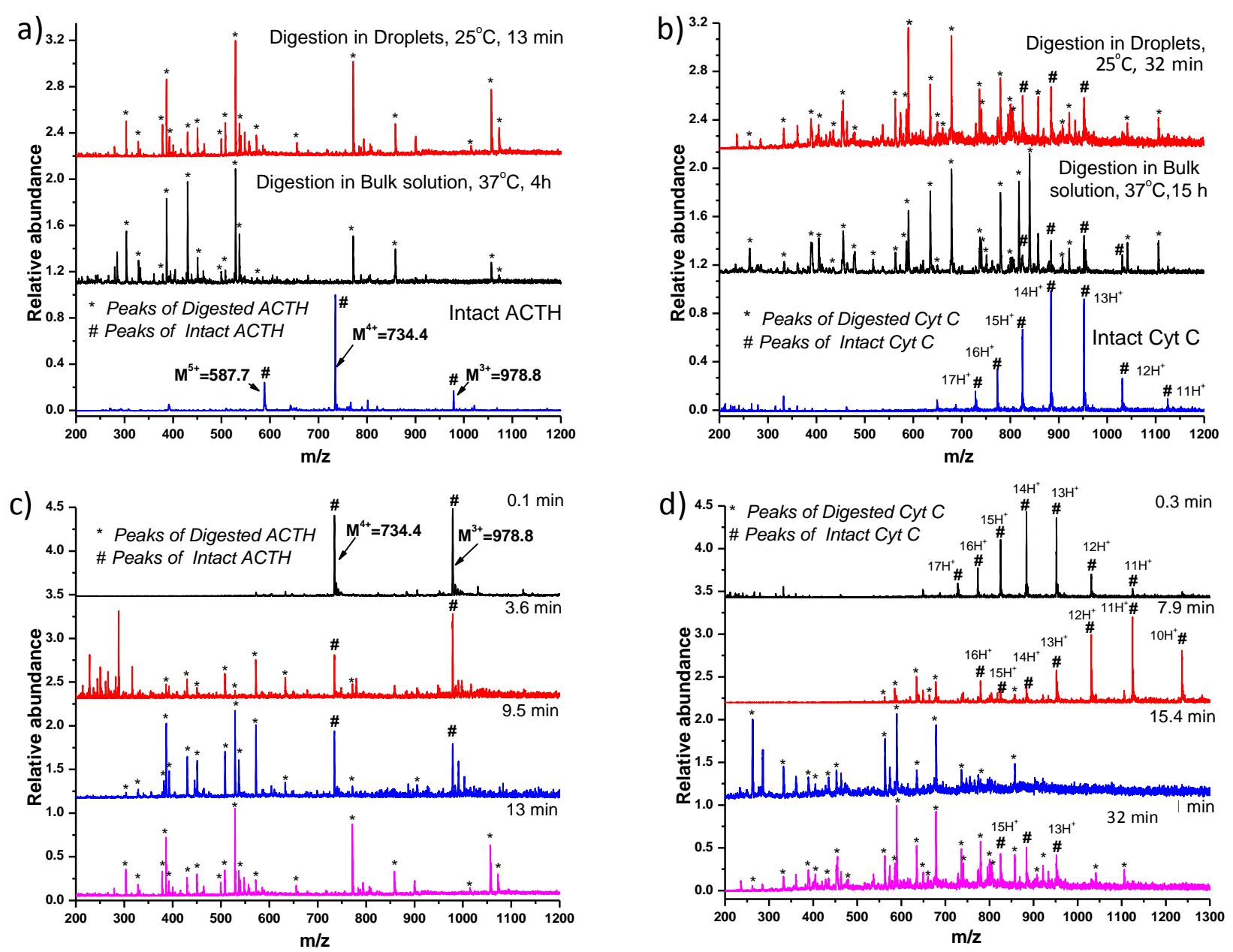

Figure SI-4. ESTASI MS spectra of the tryptic digestion in droplets at $25^{\circ} \mathrm{C}$ and in the bulk solution at $37^{\circ} \mathrm{C}$ for a) $10 \mu \mathrm{M}$ peptide $\mathrm{ACTH}(1-24)$ and b) $10 \mu \mathrm{M}$ protein cytochrome $\mathrm{C}$ digestion with trypsin concentration of $5 \mu \mathrm{g} / \mathrm{ml}$, including the spectra of intact molecules collected prior to the enzymatic reaction. ESTASI MS spectra collected at various reaction times during tryptic digestion in the droplets: c) $10 \mu \mathrm{M}$ peptide ACTH (1-24) digestion and d) $10 \mu \mathrm{M}$ protein cytochrome $\mathrm{C}$ digestion. Reaction time was defined as the time needed for freshly formed droplets to pass from the T-junction to the spyhole inside the microchip.

Obtained ESTASI MS data confirm that the tryptic digestion in droplets is much faster than in the bulk solution. ACTH digestion in the developed droplets-based microfluidic system was completed in $13 \mathrm{~min}$ at $25^{\circ} \mathrm{C}$, while it took $4 \mathrm{~h}$ to obtain the same results for bulk solution digestion performed at $37^{\circ} \mathrm{C}$. In-droplets enzymatic digestion of cytochrome $\mathrm{C}$ was finished in $32 \mathrm{~min}$ in contrast to $15 \mathrm{~h}$ for bulk reaction. Peptides observed on the ESTASI MS spectra for indroplets and bulk solution digestions of ACTH and cytochrome $\mathrm{C}$ are presented below in the Tables SI-4.1 and SI-4.2 respectively.

ESTASI MS results of performed in-droplets tryptic digestion show the possibility to efficiently perform such single-phase reactions using developed spyhole microfluidic system. 
Table SI-4.1. Peptides identified by ESTASI MS during ACTH digestion by trypsin

${ }^{1}$ Presented sequences of identified peptides include the main amino acid sequence and the amino acids before and

\begin{tabular}{|c|c|c|c|c|c|}
\hline \multicolumn{2}{|c|}{$\begin{array}{c}\text { Observed peaks after } \\
\text { diges tion, } \mathbf{m} / \mathbf{z}\end{array}$} & \multirow{2}{*}{$\begin{array}{l}\text { Charge } \\
\text { state, } z\end{array}$} & \multirow{2}{*}{$\begin{array}{l}\text { Molecular } \\
\text { weight, Da }\end{array}$} & \multirow{2}{*}{ Peptide sequence } & \multirow{2}{*}{$\begin{array}{l}\text { Missed } \\
\text { cleavages }\end{array}$} \\
\hline $\begin{array}{l}\text { Droplets in } \\
\quad 13 \mathrm{~min}\end{array}$ & $\begin{array}{l}\text { Bulk solution in } \\
4 h\end{array}$ & & & & \\
\hline- & 250.4 & 2 & 498.8 & $(\mathrm{R}) \mathrm{RPVK}(\mathrm{V})^{1}$ & 0 \\
\hline 303.4 & 303.8 & 1 & 302.6 & $(\mathrm{~K}) \mathrm{KR}(\mathrm{R})$ & 1 \\
\hline 328.3 & 328.7 & 2 & 655.1 & $(\mathrm{~K}) \mathrm{RRPVK}(\mathrm{V})$ & 1 \\
\hline 378.4 & 378.8 & 1 & 377.6 & $(\mathrm{~K}) \mathrm{VYP}(-)^{2}$ & 0 \\
\hline 386.3 & 386.7 & 2 & 771.0 & (R)WGKPVGK(K) & 1 \\
\hline 429.2 & 430.1 & 2 & 857.3 & (R)RPVKVYP(-) & 2 \\
\hline 450.3 & 450.8 & 2 & 899.2 & (R)WGKPVGKK(R) & 1 \\
\hline 499.4 & 499.3 & 1 & 498.4 & $(\mathrm{R}) \mathrm{RPVK}(\mathrm{V})$ & 1 \\
\hline 507.7 & 508.0 & 2 & 1013.8 & (K)RRPVKVYP(-) & 2 \\
\hline 528.8 & 528.9 & 2 & 1055.7 & (R)WGKPVGKKR(R) & 2 \\
\hline 536.8 & 537.0 & 2 & 1071.8 & $(-)$ SYSMEHFR $(W)^{3}$ & 0 \\
\hline 571.3 & 571.8 & 2 & 1142.7 & (K)KRRPVKVYP(-) & 3 \\
\hline 655.5 & - & 1 & 654.5 & $(\mathrm{~K}) \mathrm{RRPVK}(\mathrm{V})$ & 1 \\
\hline 771.6 & 771.6 & 1 & 770.6 & (R)WGKPVGK(K) & 0 \\
\hline 392.1 & - & 2 & 783.5 & $(\mathrm{~K}) \mathrm{KRRPVK}(\mathrm{V})$ & 2 \\
\hline 858.6 & 858.7 & 1 & 857.6 & (R)RPVKVYP(-) & 2 \\
\hline 1014.7 & - & 1 & 1014.6 & (K)RRPVKVYP(-) & 2 \\
\hline 1056.6 & 1056.6 & 1 & 1055.6 & (-)SYSMEHFR(W) & 0 \\
\hline 1072.6 & - & 1 & 1071.6 & $(-)$ SYSMEHFR $(\mathrm{W})^{3}$ & 0 \\
\hline
\end{tabular}

after the place of cleavage by trypsin in parentheses. The peptide sequences are identified by comparison of observed peptide molecular weights with theoretical ones using the FindPept tool on the ExPASy server (http://web.expasy.org/findpept/).

${ }^{2}$ (-) means that the peptide is generated from a terminal of the peptide.

${ }^{3}$ Peptide contains oxidized methionine residue. 
Table SI-4.2. Peptides identified by ESTASI MS during cytochrome C digestion

\begin{tabular}{|c|c|c|c|c|c|}
\hline \multicolumn{2}{|c|}{$\begin{array}{l}\text { Observed peaks after } \\
\text { digestion, } \mathbf{m} / \mathbf{z}\end{array}$} & \multirow{2}{*}{$\begin{array}{l}\text { Charge } \\
\text { s tate, } z\end{array}$} & \multirow{2}{*}{$\begin{array}{l}\text { Molecular } \\
\text { weight, Da }\end{array}$} & \multirow{2}{*}{ Peptide sequence } & \multirow{2}{*}{$\begin{array}{l}\text { Missed } \\
\text { cleavages }\end{array}$} \\
\hline $\begin{array}{c}\text { Droplet in } \\
32 \mathrm{~min}\end{array}$ & $\begin{array}{l}\text { Bulk solution } \\
\quad \text { in } 15 \mathrm{~h}\end{array}$ & & & & \\
\hline 262.2 & 262.5 & 1 & 261.4 & $(\mathrm{~K}) \mathrm{GGK}(\mathrm{H})^{1}$ & 0 \\
\hline 332.3 & 332.1 & 1 & 332.2 & $(\mathrm{~K}) \mathrm{GKK}(\mathrm{I})$ & 1 \\
\hline 390.2 & 390.5 & 2 & 778.7 & $(\mathrm{~K}) \mathrm{MIFAGIK}(\mathrm{K})$ & 0 \\
\hline 404.7 & 405.1 & 1 & 403.9 & $(\mathrm{~K}) \mathrm{TER}(\mathrm{E})$ & 0 \\
\hline 434.7 & 434.8 & 1 & 433.8 & $(\mathrm{~K}) \operatorname{ATNE}(-)^{2}$ & 0 \\
\hline 455.2 & 455.2 & 2 & 908.5 & $(\mathrm{~K}) \mathrm{MIFAGIKK}(\mathrm{K})$ & 1 \\
\hline 478.5 & 479.1 & 3 & 1433.7 & (K)HKTGPNLHGLFGR(K) & 1 \\
\hline- & 518.3 & 2 & 1035.6 & $(\mathrm{~K}) \mathrm{MIFAGIKKK}(\mathrm{T})$ & 2 \\
\hline 562.8 & 563.8 & 1 & 562.0 & $(\mathrm{~K}) \mathrm{KATNE}(-)$ & 1 \\
\hline 585.6 & 585.7 & 2 & 1169.4 & $(\mathrm{~K}) \mathrm{TGPNLHGLFGR(K)}$ & 0 \\
\hline 634.6 & 635.0 & 1 & 633.8 & $(\mathrm{~K}) \operatorname{IFVQK}(\mathrm{C})$ & 0 \\
\hline 648.5 & 648.3 & 2 & 1296.7 & $(\mathrm{~K}) \mathrm{TGPNLHGLFGRK}(\mathrm{T})$ & 1 \\
\hline 661.1 & - & 1 & 661.4 & $(\mathrm{~K}) \operatorname{KKTER}(\mathrm{E})$ & 2 \\
\hline 678.7 & 678.7 & 1 & 677.7 & $(\mathrm{~K}) \mathrm{YIPGTK}(\mathrm{M})$ & 0 \\
\hline 734.8 & 735.2 & 2 & 1470.7 & (K)TGQAPGFTYTDANK $(\mathrm{G})$ & 0 \\
\hline 740.4 & 740.5 & 2 & 1478.9 & $\begin{array}{l}\text { (K)TEREDLIAYLKK }(\mathrm{A}) \text { or } \\
(\mathrm{K}) \mathrm{KTEREDLIAYLK}(\mathrm{K})\end{array}$ & 2 \\
\hline- & 748.9 & 2 & 1495.7 & $(\mathrm{~K}) \operatorname{EETLMEYLENPK}(\mathrm{K})$ & 0 \\
\hline- & 761.9 & 1 & 762.5 & $(\mathrm{~K}) \mathrm{KIFVQK}(\mathrm{C})$ & 1 \\
\hline 779.8 & 779.7 & 1 & 778.7 & $(\mathrm{~K}) \mathrm{MIFAGIK}(\mathrm{K})$ & 0 \\
\hline 800.3 & 800.5 & 2 & 1598.8 & (R)KTGQAPGFTYTDANK(N) & 1 \\
\hline 806.2 & - & 1 & 806.5 & $(\mathrm{~K}) \mathrm{KYIPGTK}(\mathrm{M})$ & 1 \\
\hline- & 818.1 & 2 & 1634.2 & (K)IFVQKCAQCHTVEK $(\mathrm{G})$ & 1 \\
\hline- & 839.8 & 2 & 1677.7 & (K)GGKHKTGPNLHGLFGR(K) & 2 \\
\hline 857.5 & - & 2 & 1713.0 & (K)TGQAPGFTYTDANKNK(G) & 1 \\
\hline 907.7 & 907.8 & 1 & 906.7 & $(\mathrm{~K}) \mathrm{MIFAGIKK}(\mathrm{K})$ & 1 \\
\hline 921.5 & 921.4 & 2 & 1840.9 & (R)KTGQAPGFTYTDANKNK(G) & 2 \\
\hline 1041.4 & 1041.8 & 2 & 2081.3 & $(\mathrm{~K})$ GITWKEETLMEYLENPK $(\mathrm{K})$ & 1 \\
\hline 1105.8 & 1105.8 & 2 & 2209.7 & (K)GITWKEETLMEYLENPKK(Y) & 2 \\
\hline
\end{tabular}

${ }^{1}$ Presented sequences of identified peptides include the main amino acid sequence and the amino acids before and after the place of cleavage by trypsin in parentheses. The peptide sequences are identified by comparison of observed peptide molecular weights with theoretical ones using the FindPept tool on the ExPASy server (http://web.expasy.org/findpept/).

2.(-) means that the peptide is generated from a terminal of the protein. 


\section{SI-5: $\beta$-lactoglobulin and $\alpha$-tocopheryl acetate interaction}

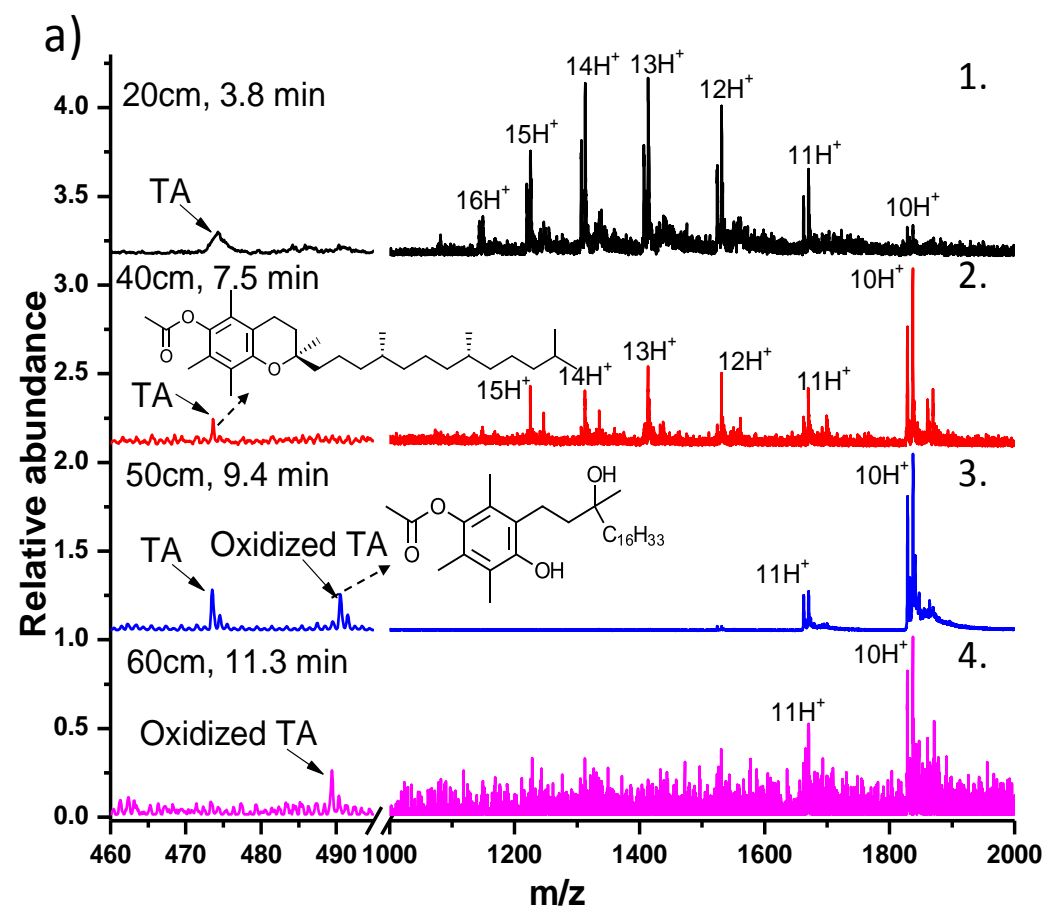

b)

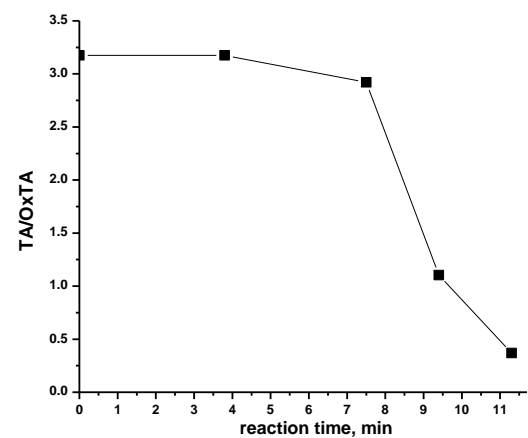

c)

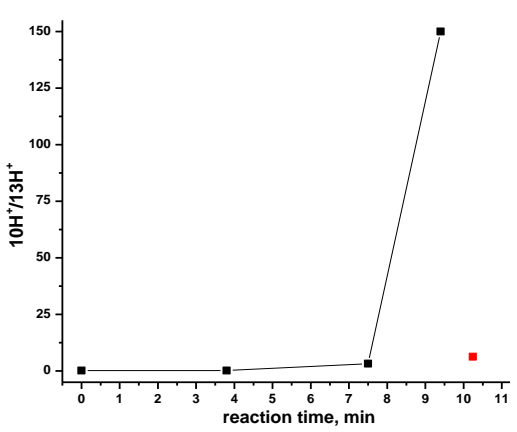

Figure SI-5. ESTASI MS spectra of $\beta$-lactoglobulin (LGB) and $\alpha$-tocopheryl acetate (TA) biphasic interaction in droplets: 5.4 $\mu \mathrm{M}$ LGB $(\mathrm{A}+\mathrm{B})$ in the water phase and $135 \mu \mathrm{M}$ TA in DCE. Double peak observed for each LGB charge state corresponds to the two isoforms (A+B). a) MS spectra from the droplets at various reaction times. Reaction time was defined as the time needed for freshly formed droplets to pass from the T-junction to the spyhole inside the microchip. b) Time dependence of the ratio between MS peak intensities of TA and OxTA. c) Time dependence of the ratio between LGB MS peak intensities for charge states $\mathrm{z}=10$ and $\mathrm{z}=13$. The red point corresponds to the moment when aggregation of reduced LGB already occurs.

During the biphasic reaction (Figure SI-5.a) LGB changed its charge distribution on MS spectra from normal (1) to the intermediate (2) and finally to the one of the reduced molecule (3), while TA was oxidized (4). The progress of this redox reaction can be followed by comparing the MS peak intensities of TA and oxidized TA (OxTA) at various reaction times. As displayed in Figure SI-5.b, the TA/OxTA ratio was decreasing with time indicating TA oxidation. At the same time, the ratio between LGB MS peak intensities for charge states $\mathrm{z}=10$ and $\mathrm{z}=13$ was increasing with the reaction progress until reduced LGB started to aggregate (red point, Figure SI-5.c). This shows the reduction of LGB as the peak with charge state $\mathrm{z}=13$ is predominant for the native protein molecule, while the peak with charge state $\mathrm{z}=10$ is predominant for the reduced LGB. 


\section{SI-6: Tandem MS analysis of $\alpha$-tocopherolyl acetate and its oxidation product}

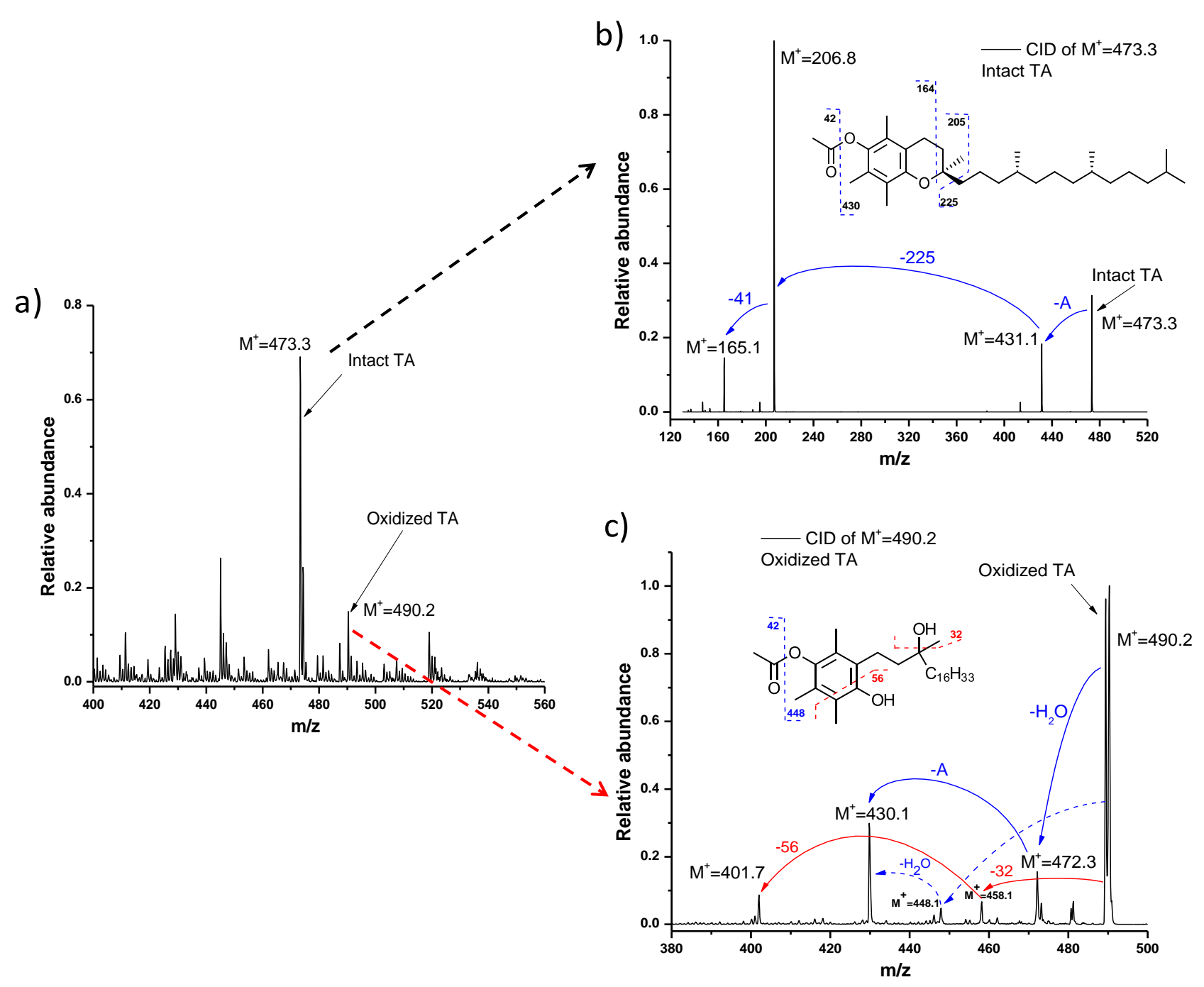

Figure SI-6. Tandem MS analysis of $\alpha$-tocopheryl acetate (TA) and its oxidation product. a) ESI-MS spectrum of TA $\left(\mathrm{M}^{+}=473.3 \mathrm{Da}\right)$ and its oxidized form $\left(\mathrm{M}^{+}=490.2 \mathrm{Da}\right)$ obtained during the reaction with LGB in the shake flask reaction. b) MS-MS spectrum of the intact TA ion, $\mathrm{M}^{+}=$ 473.3 Da, fragmented via collision induced dissociation (CID). c) MS-MS spectrum of the oxidized TA ion, $\mathrm{M}^{+}=490.2 \mathrm{Da}$, fragmented via CID. Fragmentation of the molecules is schematically shown on their chemical structures. A: acetic group.

TA interaction with LGB leads to its oxidation and the formation of oxidized TA. Performance of MS/MS analysis allows identification of the oxidized TA structure. As can be concluded from the obtained MS/MS spectrum of the intact TA ion, $\mathrm{M}^{+}=473.3$, presented above, during its CID fragmentation the acetic group ( $\mathrm{MW}=42 \mathrm{Da}$ ) was easily lost forming the fragment ion $\mathrm{M}^{+}=431.1$. Consequently, this ion lost the fatty tail ( $\mathrm{MW}=225 \mathrm{Da}$ ) and formed the ion $\mathrm{M}^{+}=206.8$. The absence of fatty tail provoked further loss of a part of the molecule (MW $=41 \mathrm{Da}$ ) and formation of ion $\mathrm{M}^{+}=165.1 \mathrm{Da}$, as indicated on Figure SI-6.b. 
Similar behavior was observed for the CID fragmentation of oxidized TA ion, $\mathrm{M}^{+}=490.2$. The loss of the acetic group ( $\mathrm{MW}=42 \mathrm{Da}$ ) led to formation of the ion $\mathrm{M}^{+}=448.1$, which further gave the ion $\mathrm{M}^{+}=430.1$ by losing a water molecule. However, this process (dashed blue arrows on the Figure SI-6.c) was less efficient than the direct loss of $\mathrm{H}_{2} \mathrm{O}$ molecule from the intact oxidized TA, which provided the fragmentation ion $\mathrm{M}^{+}=472.3$. Then this ion lost easily the acetic group, forming the same ion $\mathrm{M}^{+}=430.1 \mathrm{Da}$ (solid blue arrows on the Figure SI-6.c).

Meanwhile, there was a third fragmentation process, which did not include the loss of the acetic group (solid red arrows on the Figure SI-6.c). It started from the loss of the fragment with $\mathrm{MW}=32 \mathrm{Da}$ forming the ion $\mathrm{M}^{+}=458.1$. Then this ion lost a fragment with $\mathrm{MW}=56 \mathrm{Da}$ providing the ion $\mathrm{M}^{+}=401.7$. Such a fragmentation pathway is possible only because of the presence of the acetic group in the oxidized TA and provides evidence towards the proposed chemical structure of this molecule and TA oxidation due to the interaction with LGB. 


\section{SI-7: Tagging free cysteine residues in the reduced $\beta$-lactoglobulin with benzoquinone}

Each isoform (A or B) of the native $\beta$-lactoglobulin (LGB) molecule possesses one free cysteine residue, ${ }^{[1]}$ which can be tagged by benzoquinone (BQ). To perform this control reaction, the water droplets containing LGB and BQ were generated and transferred inside the microchip with the spyhole without adding $\alpha$-tocopheryl acetate (TA) to the DCE phase. The ESTASI MS spectra obtained from these water droplets are presented below in Figure SI-7.1.

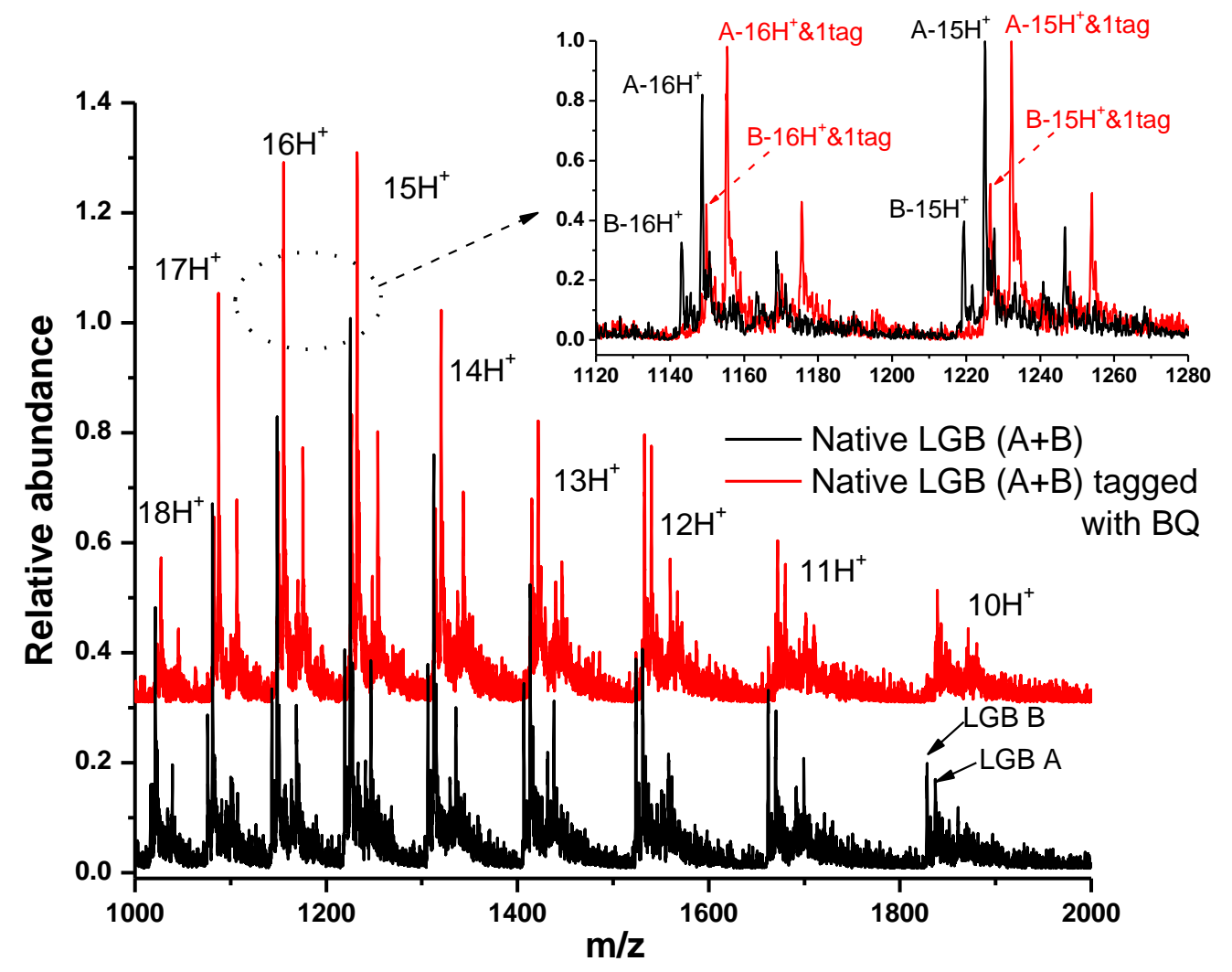

Figure SI-7.1. Tagging free cysteine residue by $2.5 \mathrm{mM}$ BQ in the native LGB (A and B isoforms, $5.4 \mu \mathrm{M}$ ). ESTASI MS spectra of pure native LGB (black spectra) and native LGB tagged with BQ (red spectra). The zoomed region represents the LGB peaks with charge states $\mathrm{z}=16$ and $\mathrm{z}=15$ to show the mass-to-charge $(\mathrm{m} / \mathrm{z})$ shift due to one tag by BQ for both protein isoforms. $\mathrm{nH}^{+}$: $\mathrm{n}$ protonated ions; $\mathrm{A}(\mathrm{B})-\mathrm{nH}^{+}$\& 1 tag: $\mathrm{n}$ protonated $\mathrm{A}(\mathrm{B})$ isoform of $\mathrm{LGB}$ with one BQ tag.

As a mixture of LGB isoforms A and B was used, two series of peaks corresponding to isoforms $\mathrm{B}$ and $\mathrm{A}$ were always presented for every charge state. BQ, MW= $108 \mathrm{Da}$, tagged one free cysteine residue in each LGB isoform and a clear $\mathrm{m} / \mathrm{z}$ shift related to the addition of $108 \mathrm{Da}$ (one BQ tag) was observed for both isoforms (Figure SI-7.1, zoomed region).

The native LGB molecule (each isoform) includes two disulfide bridges, ${ }^{[12]}$ which would lead to the formation of four free cysteine residues after reduction by TA. To check the 
appearance of additional free cysteine residues in the LGB molecule due to its reduction by TA, the water droplets containing LGB were generated in the presence of TA and BQ in the DCE phase, as BQ is more soluble in oil phase. ESTASI MS spectra obtained from the se droplets are shown below in Figure SI-7.2.
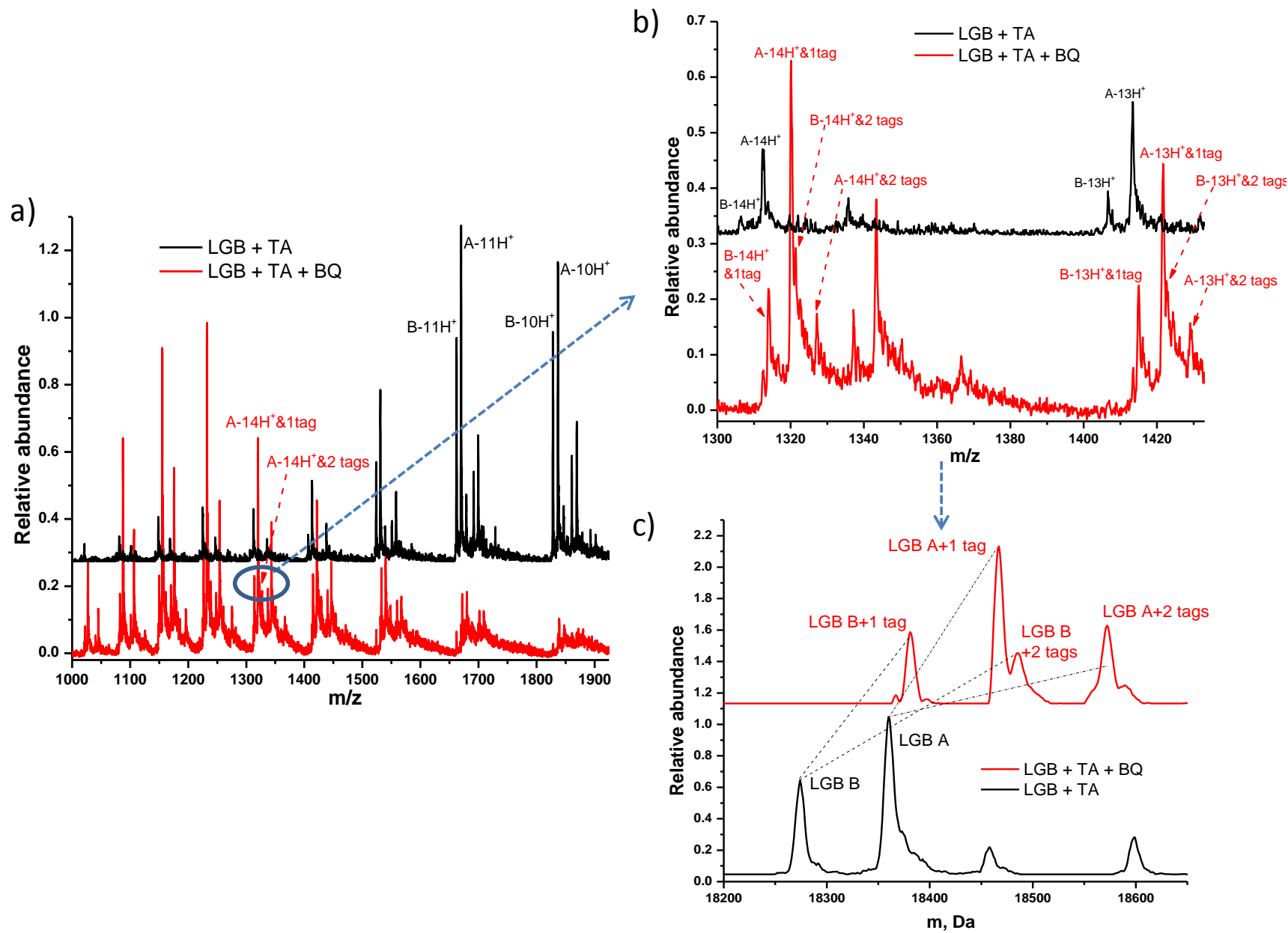

Figure SI-7.2. Tagging free cysteine residues by $2.5 \mathrm{mM}$ BQ in the LGB (A and B isoforms, 5.4 $\mu \mathrm{M})$ reduced by $135 \mu \mathrm{M}$ TA. a) Full ESTASI MS spectra of TA reduced LGB (black spectrum) and TA reduced LGB tagged with BQ (red spectrum). b) Magnified region represents LGB peaks with charge states $\mathrm{z}=14$ and $\mathrm{z}=13$ to show $\mathrm{m} / \mathrm{z}$ shifts due to one or two tags by $\mathrm{BQ}$ for both protein isoforms. c) Deconvoluted spectra of TA reduced LGB (black spectrum) and TA reduced LGB tagged with BQ (red spectrum). A(B)- $\mathrm{nH}^{+}$: n protonated A (B) isoform of LGB; $\mathrm{A}(\mathrm{B})-\mathrm{nH}^{+}$ \& 1 (2) $\operatorname{tag}(\mathrm{s})$ : $\mathrm{n}$ protonated $\mathrm{A}(\mathrm{B})$ isoform of LGB with one (two) BQ $\operatorname{tag}(\mathrm{s})$.

Besides the $\mathrm{m} / \mathrm{z}$ shift corresponding to the addition of $108 \mathrm{Da}$ due to one $\mathrm{BQ}$ tag, another $\mathrm{m} / \mathrm{z}$ shift related to the addition of 216 Da owing to two BQ tags, was found for both LGB isoforms (Figure SI-7.2.b) and was not previously observed for the native protein. On the deconvoluted ESTASI MS spectra LGB peaks corresponding to the addition of two BQ tags are clearly observed (Figure SI-7.2.c). The presence of a second BQ tag in the LGB molecule is possible only if additional free cysteine residues are present in the protein structure as a result of 
disulfide bridge reduction by TA. This fact further proves the idea of redox reaction between LGB and TA.

Considering the peaks of LGB isoforms with more than two BQ tags, they were difficult to observe on MS spectra owing to their lower abundance, lower intensities and the high noise level created by excess of BQ in the water droplets. One of the possible reasons for the low abundance of multiple BQ tags is the occurrence of side reaction between TA and BQ, as the later compound is added to the oil phase in a large excess in comparison with LGB and TA. Therefore, BQ could oxidize TA as well, decreasing the rate of LGB-TA redox reaction and explaining the charge distribution of LGB molecule observed in ESTASI MS spectrum in Figure SI-7.2.a, red line. The presence of two BQ tags indicates that LGB is reduced by TA, but only partially, still providing the charge distribution of a native protein molecule.

\section{References}

[1] L. Qiao, R. Sartor, N. Gasilova, Y. Lu, E. Tobolkina, B. Liu, H. H. Girault, Anal. Chem. 2012, 84, 7422-30.

[2] N. Gasilova, L. Qiao, D. Momotenko, M. R. Pourhaghighi, H. H. Girault, Anal. Chem. 2013, 85, 6254-63.

[3] Q. Li, J. Pei, P. Song, R. T. Kennedy, Anal. Chem. 2010, 82, 5260-7.

[4] J. Ji, Y. Zhao, L. Guo, B. Liu, C. Ji, P. Yang, Lab Chip 2012, 12, $1373-7$.

[5] J. Ji, L. Nie, L. Qiao, Y. Li, L. Guo, B. Liu, P. Yang, H. H. Girault, Lab Chip 2012, 12, 2625-9.

[6] R. T. Kelly, J. S. Page, I. Marginean, K. Tang, R. D. Smith, Angew. Chem. Int. 2009, 48, 6832-5.

[7] A. J. Olaya, D. Schaming, P.-F. Brevet, H. Nagatani, T. Zimmermann, J. Vanicek, H.-J. Xu, C. P. Gros, J.-M. Barbe, H. H. Girault, J. Am. Chem. Soc. 2012, 134, 498-506.

[8] A. J. Olaya, D. Schaming, P.-F. Brevet, H. Nagatani, H.-J. Xu, M. Meyer, H. H. Girault, Angew. Chem. Int. Ed. 2012, 51, 6447-51.

[9] P. Ge, T. K. Todorova, I. H. Patir, A. J. Olaya, H. Vrubel, M. Mendez, X. Hu, C. Corminboeuf, H. H. Girault, Proc. Natl. Acad. Sci. U. S. A. 2012, 109, 11558-63.

[10] M. a Méndez, Z. Nazemi, I. Uyanik, Y. Lu, H. H. Girault, Langmuir 2011, 27, 13918-24.

[11] M. a Méndez, M. Prudent, B. Su, H. H. Girault, Anal. Chem. 2008, 80, 9499-507.

[12] G. Kontopidis, C. Holt, L. Sawyer, J. Dairy Sci. 2004, 87, 785-96. 
